\title{
Supplementary of
}

Source apportionment of highly time resolved trace elements during a firework episode from a rural freeway site in Switzerland 5

Pragati Rai et al.

Correspondence to: André S. H. Prévôt (andre.prevot@psi.ch) and Markus Furger (markus.furger@psi.ch) 


\section{S1. Preliminary source apportionment analysis and factor identification:}

The first step in the source apportionment analysis is to perform a bilinear model without any a-priori information in the modelled matrices (F and G) (unconstrained PMF) for different numbers of factors, e.g., three to ten factors (Crippa et al., 2014). The unconstrained PMF solution resulted in mixed factors, such as sea salt mixed with fireworks even for higher

5 number of factors (Fig S1). The separation of the sea salt factor from fireworks was done as follows:

1. The input data set was divided into two parts: fireworks days (30 July-4 August) and Non-fireworks days (all days except 30 July-4 August).

2. Unconstrained PMF was performed at different number of factors on both data sets separately.

3. The fireworks profile and sea salt profile were selected from a PMF run conducted on fireworks data set and nonfireworks data set, respectively.

4. A secondary sulfate factor was observed (mostly characterized by elemental $\mathrm{S}$ with, $91 \%$ of total factor composition) at the 9 factor solution (Fig. S1), which correlates very well with ACSM sulfate $\left(R^{2}=0.91\right)$.

5. The factor profiles of secondary sulfate, fireworks and sea salt were constrained in the PMF. In addition, the time series of the secondary sulfate factor was constrained too to avoid mixing between this time series and that of the firework factors.

6. Various sensitivity tests were performed by varying the $a$-value of the constrained data.

Backward trajectory inspection revealed a predominance of continental air masses during the firework event, excluding the influence of sea salt. The absolute $\mathrm{Cl}$ concentration during fireworks period was used as background $\mathrm{Cl}$ concentration by replacing the fireworks data points with linear interpolation between two non-fireworks data points. This information was used to separate sea salt factor time series from fireworks time series. It was done by constraining the background $\mathrm{Cl}$ time series (only for fireworks data points) in the sea salt factor time series. ME-2 was performed from 4 to 10 factors on the whole data set with different seeds. 


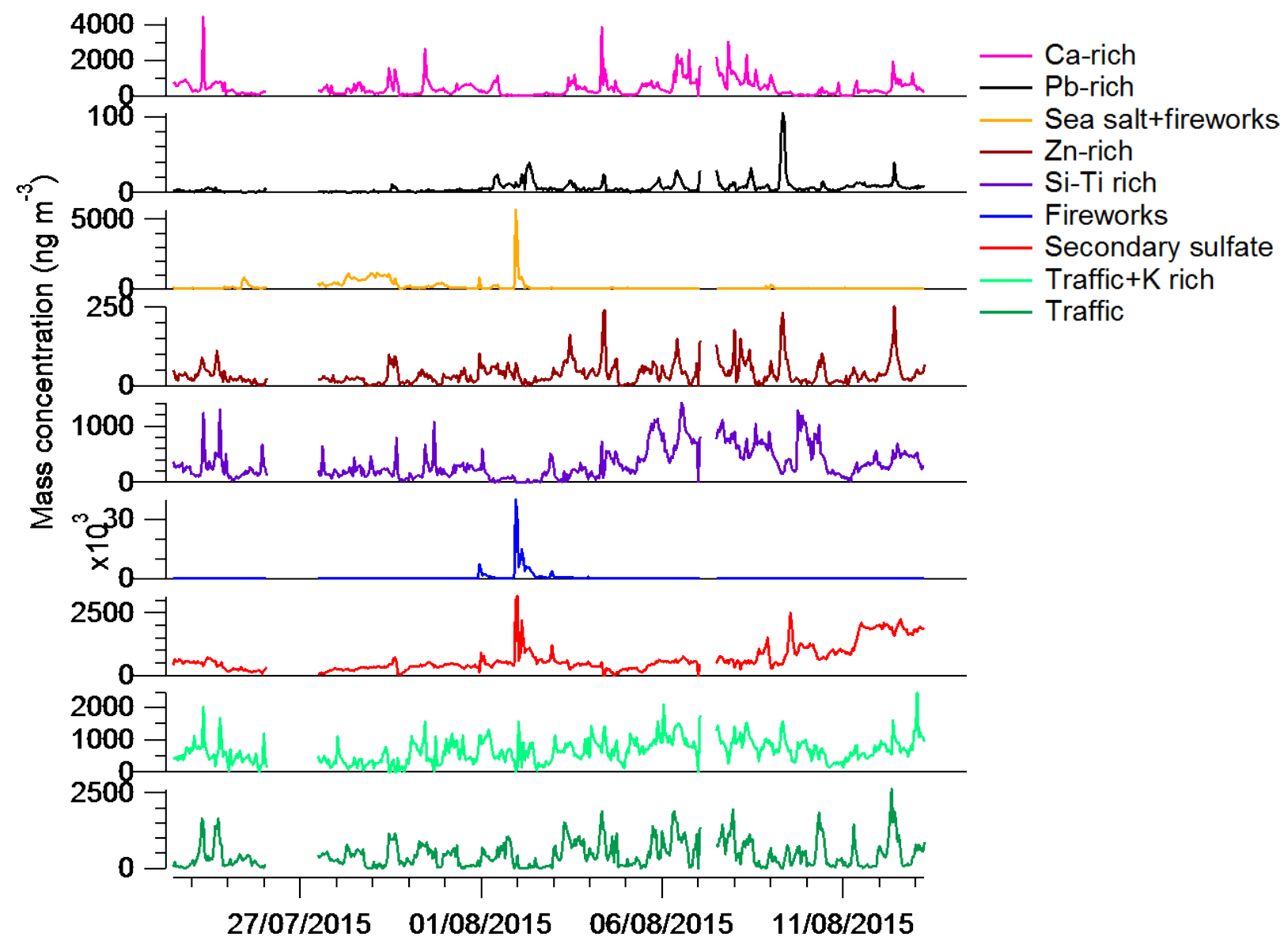

Figure S1: Unconstrained PMF with a nine-factor solution.

Based on $\mathrm{Q}_{\text {avg, }}$ defined as $\frac{\sum_{i=1}^{m} \sum_{j=1}^{n}\left(\frac{e_{i j}}{s_{i j}}\right)^{2}}{n * m}$ ( $n$ : sample time series, $m$ : number of variables), the model explains the data variability very well when allowing for eight factors (Fig S2). Furthermore, we access the change in time-dependent $\mathrm{Q}_{\mathrm{avg}, \mathrm{i}}$, $5 \frac{\sum_{i=1}^{m} \Sigma_{j=1}^{n}\left(\frac{e_{i j}}{s_{i j}}\right)^{2}}{n}$, when increasing the number of factors i.e., $\Delta \mathrm{Q}_{\mathrm{avg}, \mathrm{i}}$; contribution to Q for $(p)$-factor solution minus that of the $(p+1)$-factor solution (Fig S3). A significant decrease in $\Delta \mathrm{Q}_{\text {avg,i }}$ indicates that structure in the residuals disappeared with the additional factor. The removed structure is evident up to eight factors. Increasing the number of factors to nine yields a new mixed factor of traffic-related and background dust factors (Fig. S1). Overall, a best ME-2 solution was observed up to a number of factors equal to eight. 
For the 8-factor solution, we assess how well the different variables are explained by PMF using the quantity $\Delta \mathrm{Q}_{\mathrm{avg}, \mathrm{j}}$ $\frac{\sum_{i=1}^{m} \sum_{j=1}^{n}\left(\frac{e_{i j}}{s_{i j}}\right)^{2}}{m}$

(Fig S4). $\mathrm{Q}_{\mathrm{avg}, \mathrm{j}}$ shows that with 8 factors all variables are explained within their measurement uncertainty except $\mathrm{Si}$ and $\mathrm{Pb}$. This might be linked to an underestimation of the measurement uncertainty itself.

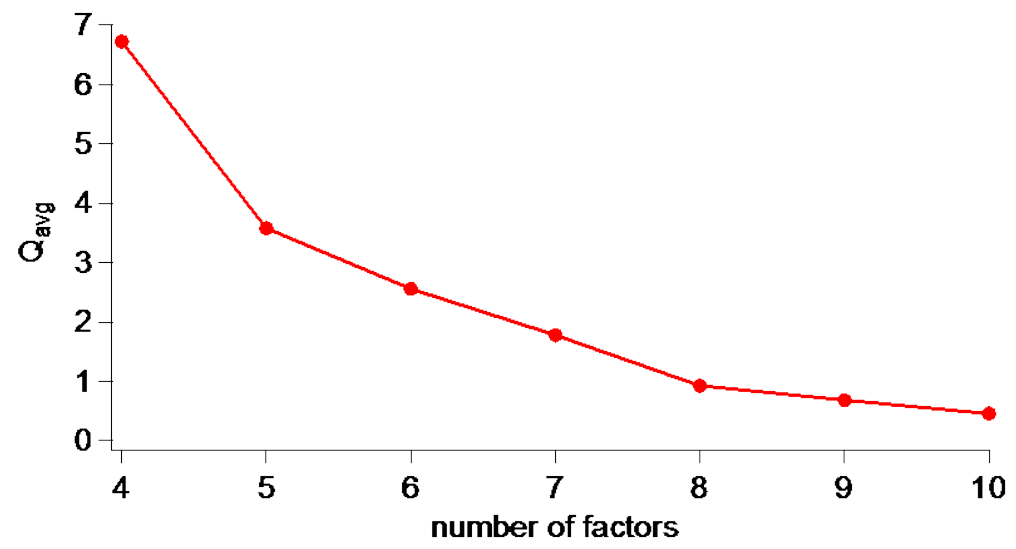

5 Figure $\mathbf{S 2}: \mathbf{Q}_{\text {avg }}$ as a function of the number of factors. 


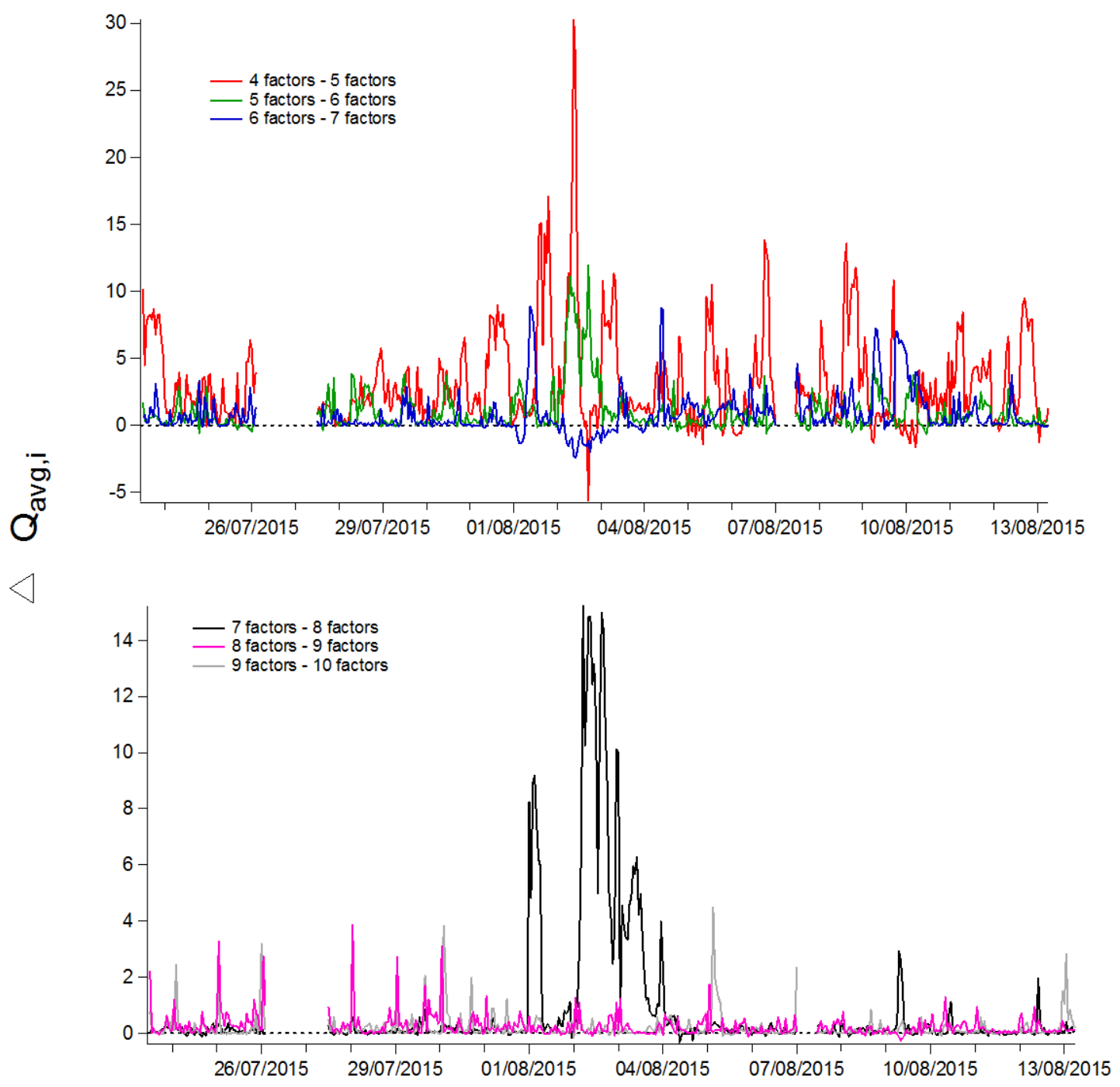

Figure S3: Change in time-dependent contribution of $\mathbf{Q}_{\mathrm{avg}, \mathrm{i}}\left(\Delta \mathbf{Q}_{\mathrm{avg}, \mathrm{i}}\right)$ as a function of the number of factors. 


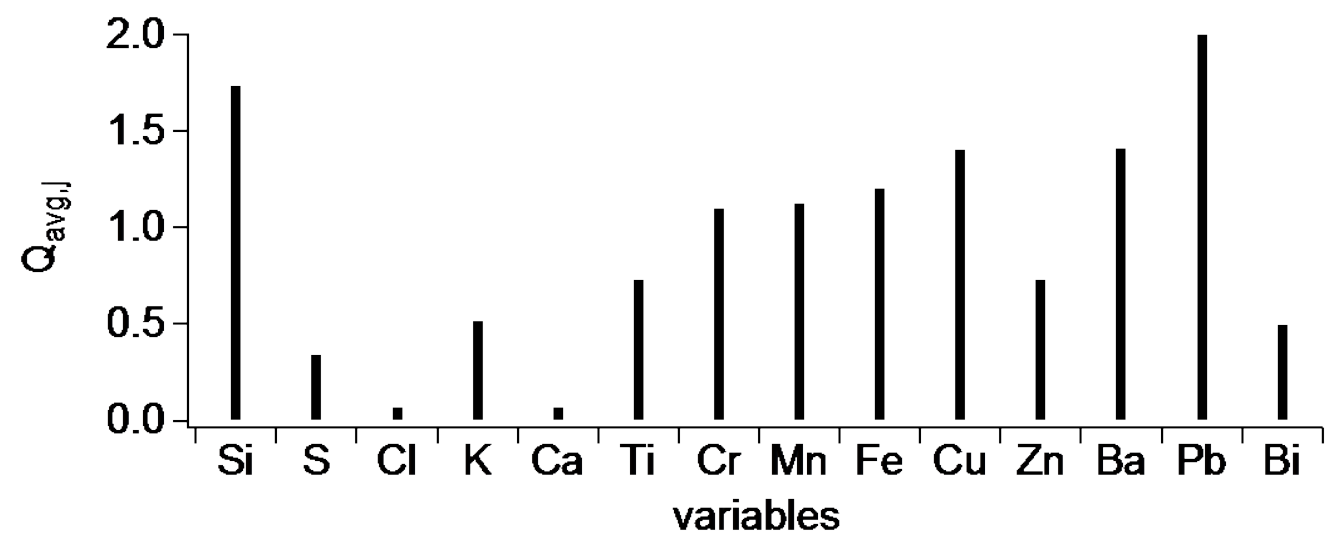

Figure S4: $\mathbf{Q}_{\text {avg }}$ as a function of variables for the 8-factor solution. 

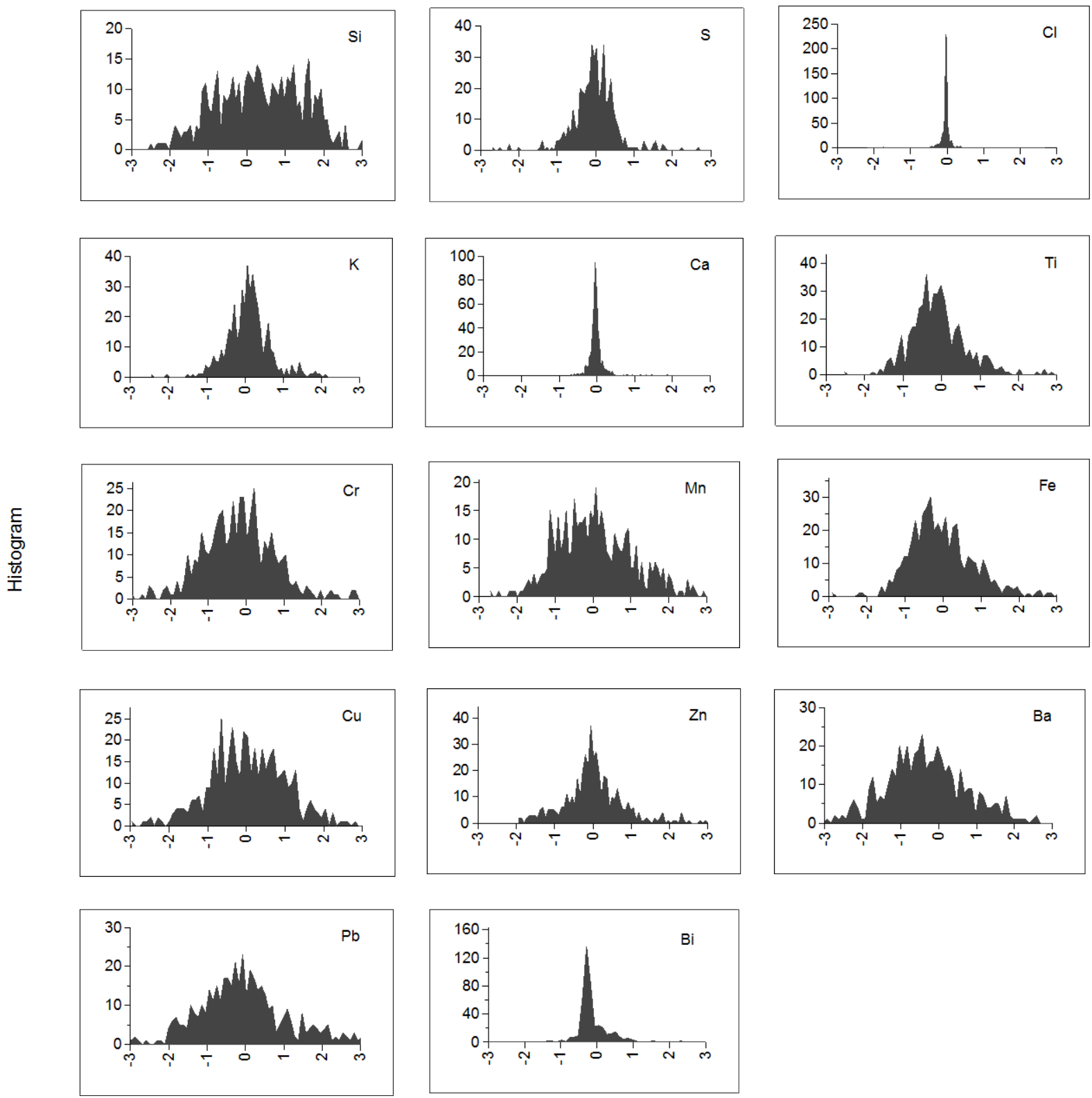

Figure S5: Histogram of variables as a function of residuals weighted by the uncertainty (residual/uncertainty) for the 8-factor solution. 


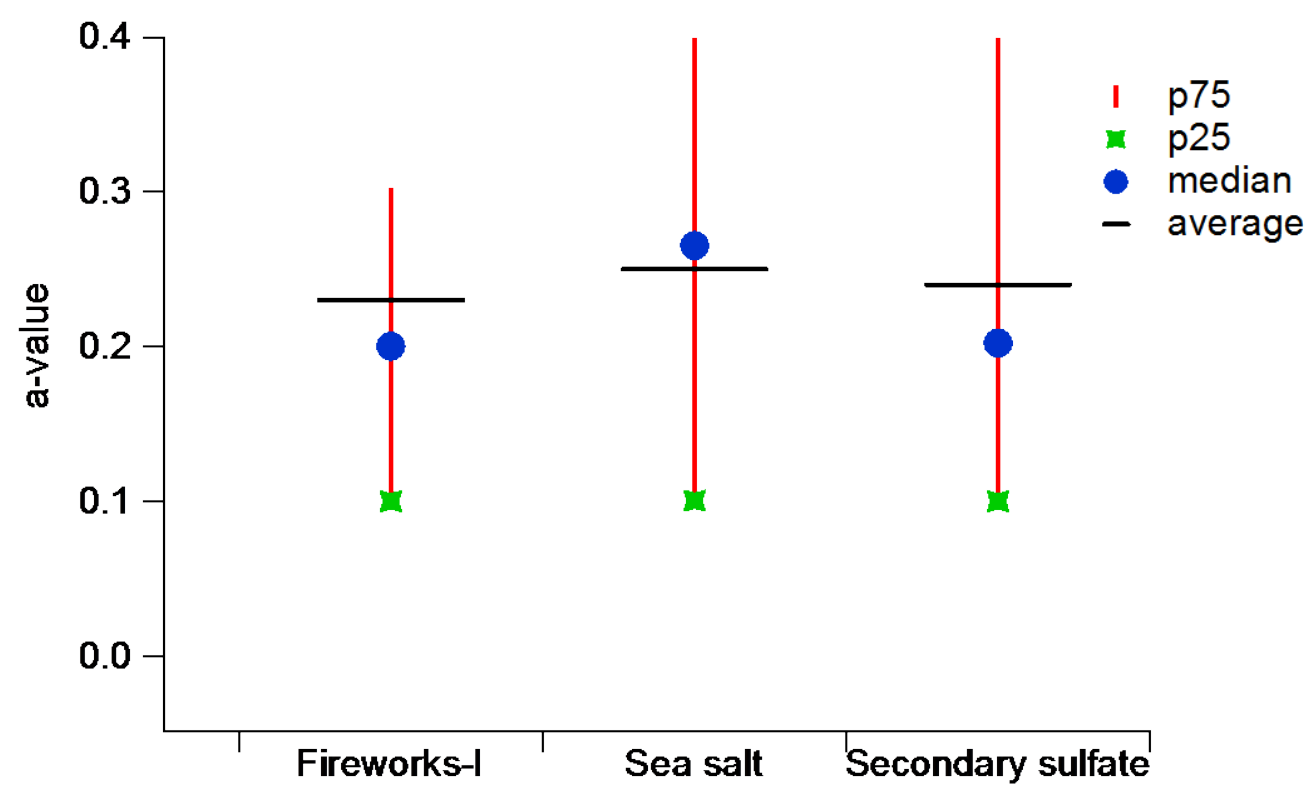

Figure S6: $a$-value statistics of the accepted solutions. $a$-values between 0 to 0.5 were explored during BS analysis. The average $a$ value of the selected solutions was ranging from 0.2 to 0.3 for the constrained factors. The selected $a$-values were homogeneously distributed over that range.

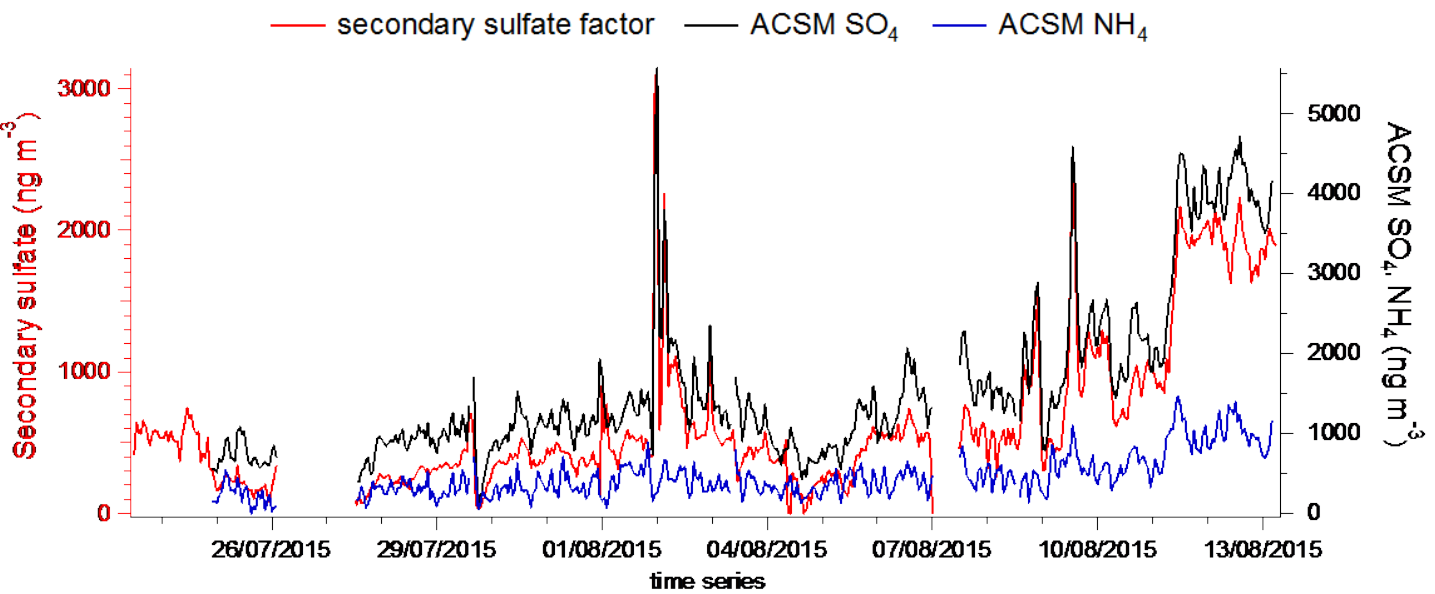

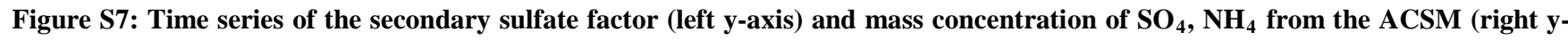
axis). 


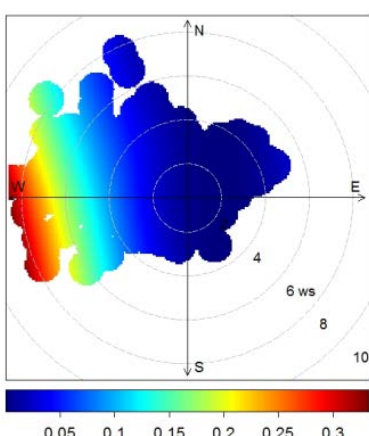

$\begin{array}{llllll}0.05 & 0.1 & 0.15 & 0.2 & 0.25 & 0.3\end{array}$

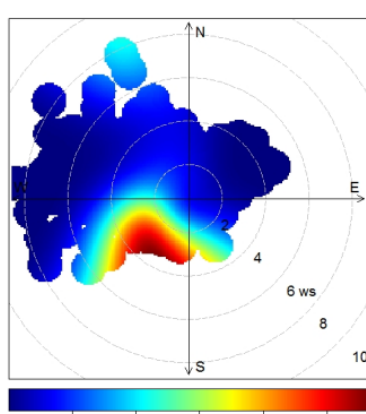

$\begin{array}{cccc}0.02 & 0.04 \quad 0.06 \quad 0.08 \\ \text { Background dust }\end{array}$

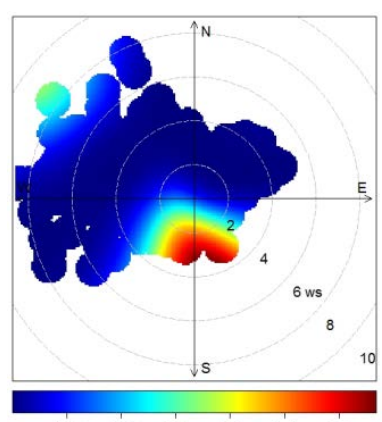

$\begin{array}{llllll}0.02 & 0.04 & 0.06 & 0.08 & 0.1 & 0.12\end{array}$

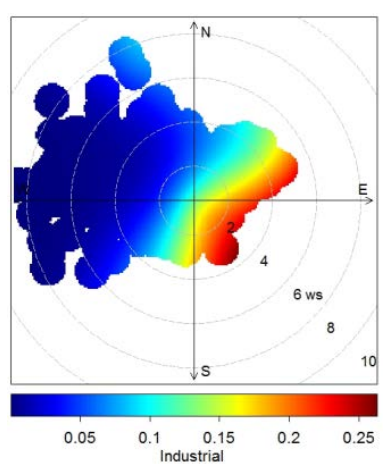

Figure S8: CBPF analysis (at $90^{\text {th }}$ percentile) of factors in terms of wind speed $\left(\mathrm{m} \mathrm{s}^{-1}\right)$ and wind direction. The color code represents the probability of the factor contribution.

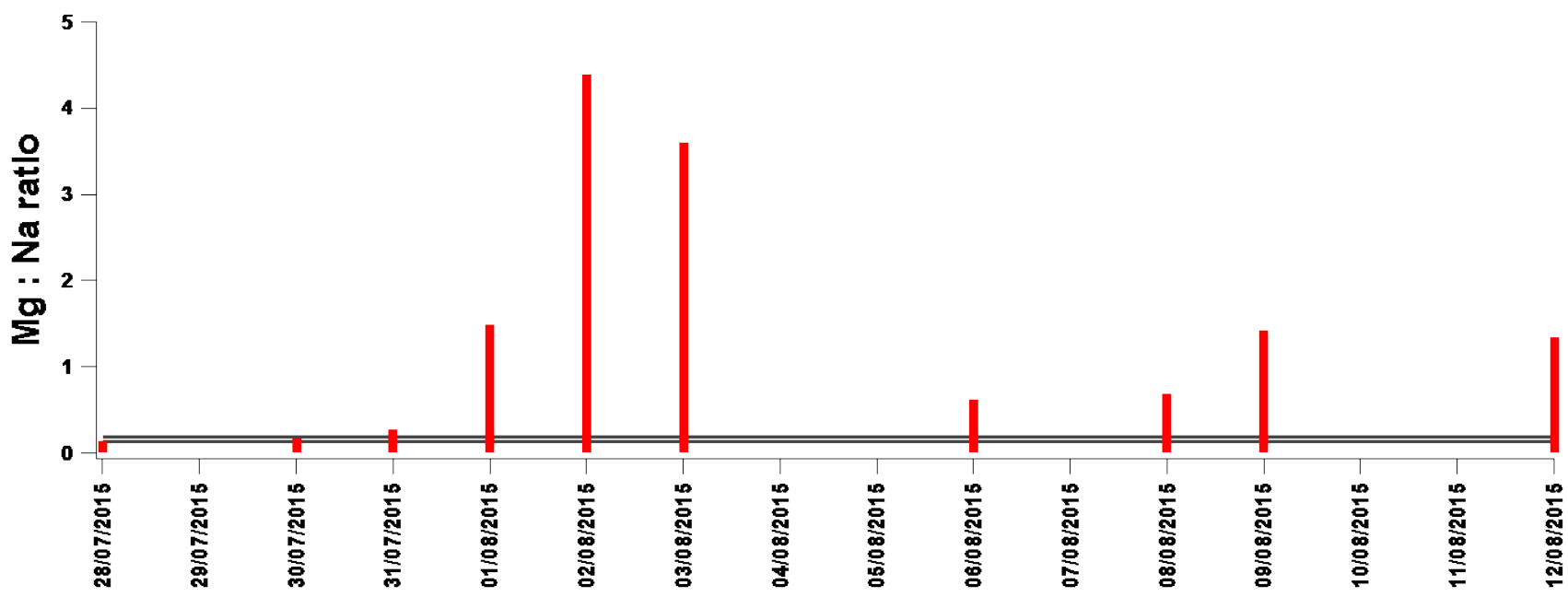

5 Figure S9: Mg:Na ratio (red bars) for 24-h filter data analyzed by ICP-OES. The gray lines represent the Mg:Na ratio range $(0.132-0.185)$ in marine aerosols. 

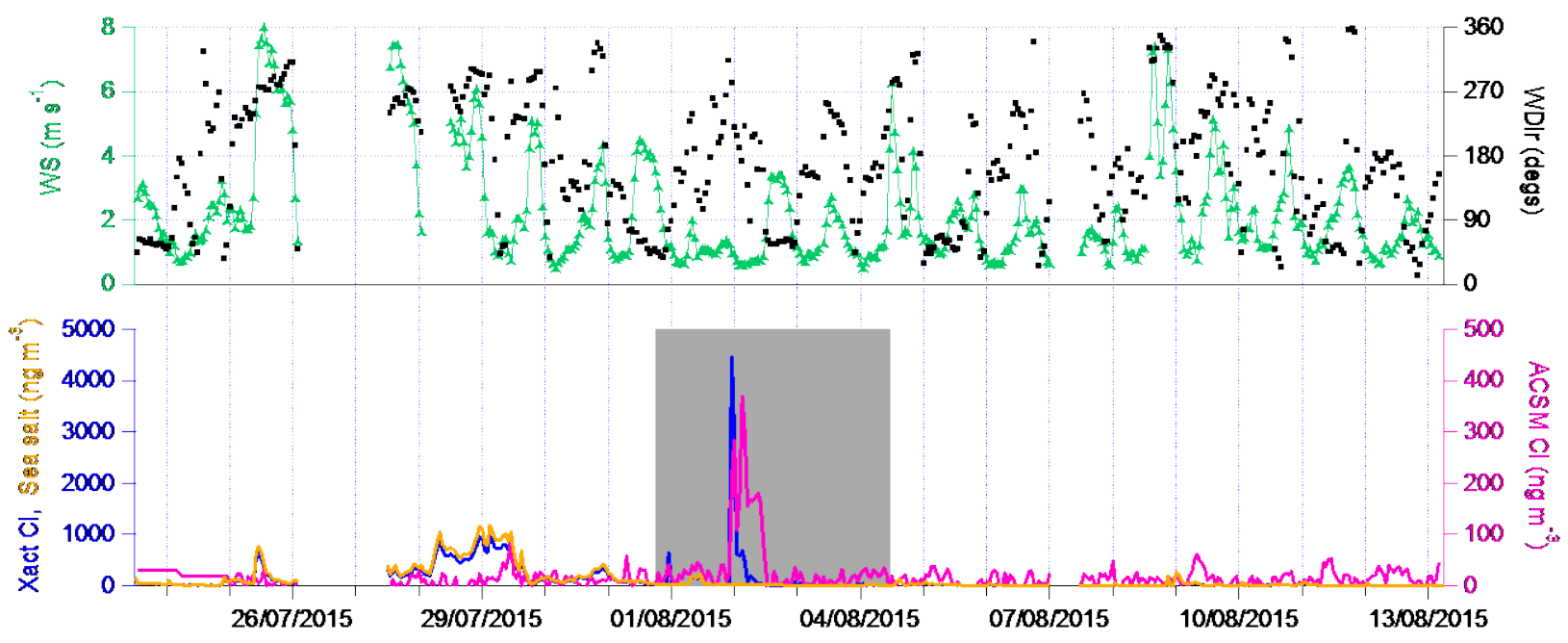

Figure S10: Bottom panel: time series of the Cl concentration from Xact and sea salt factor (left y-axis) from PMF solution and ACSM chloride concentration (right $\mathrm{y}$-axis); top panel: wind speed (WS in $\mathrm{m} \mathrm{s}^{-1}$ ) and wind direction (WDir in degree) during measurement period, grey area in bottom panel represents fireworks days.

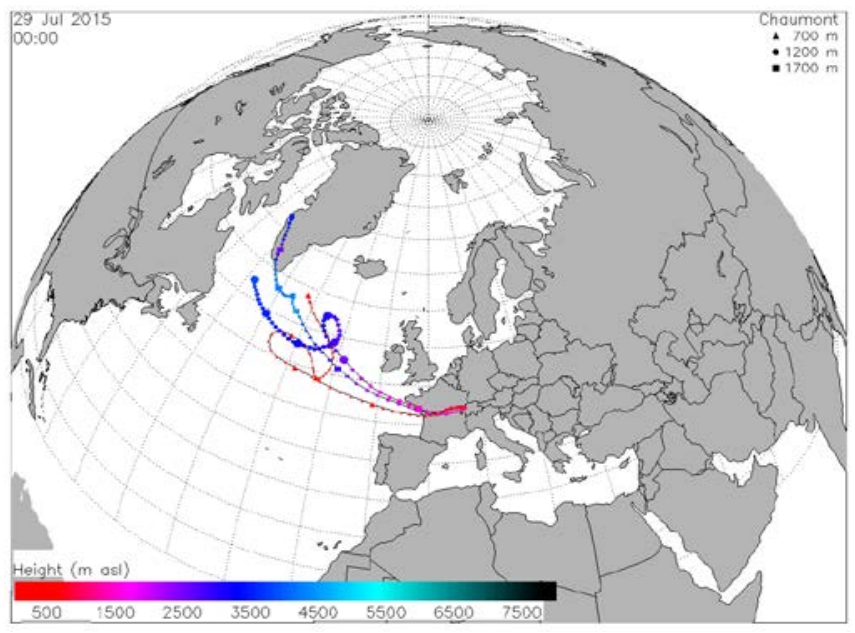

Figure S11: Backward trajectory analysis at different heights during a sea salt event. 


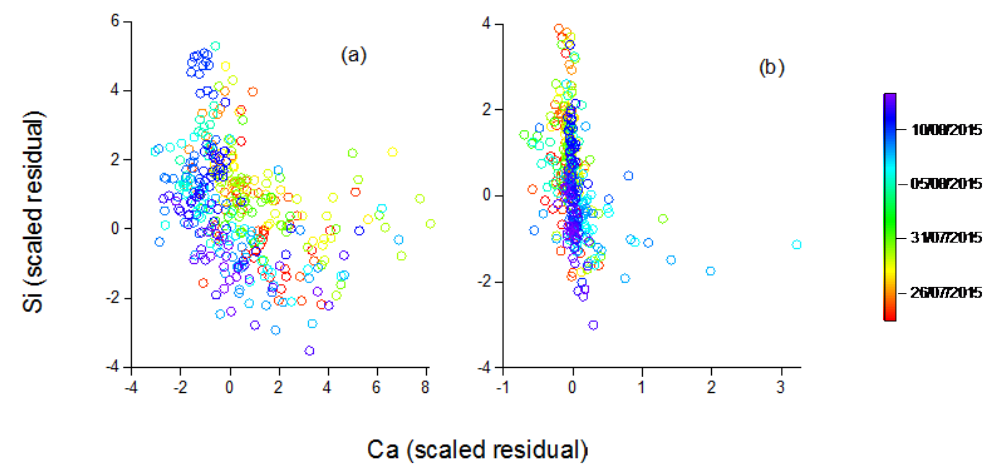

Figure S12: Scatter plot between Si and Ca scaled residuals: (a) PMF solution with one dust factor; (b) PMF solution with two dust factors.

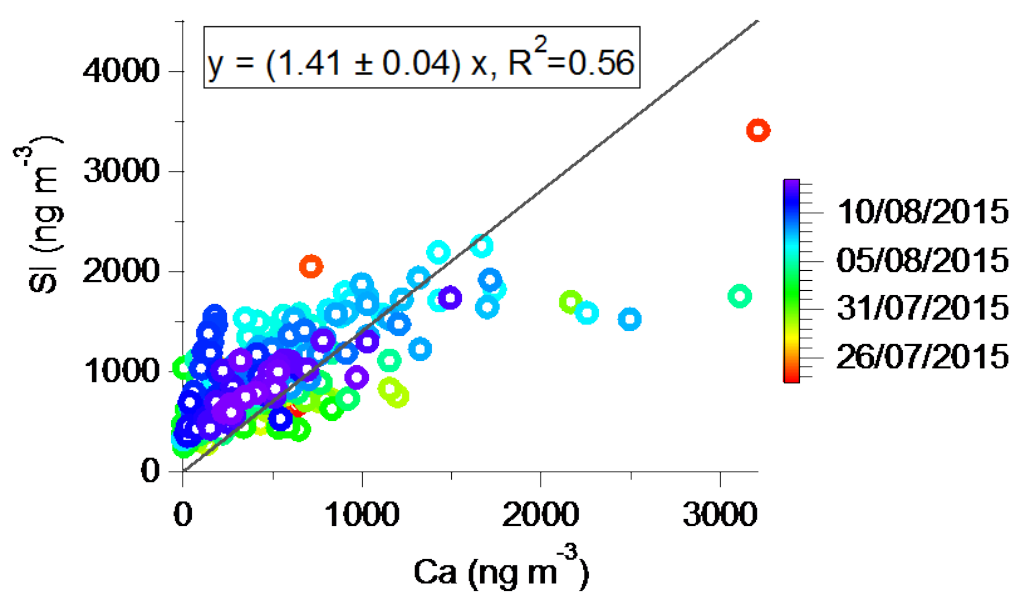

5 Figure S13: Scatter plot between Si and Ca. 


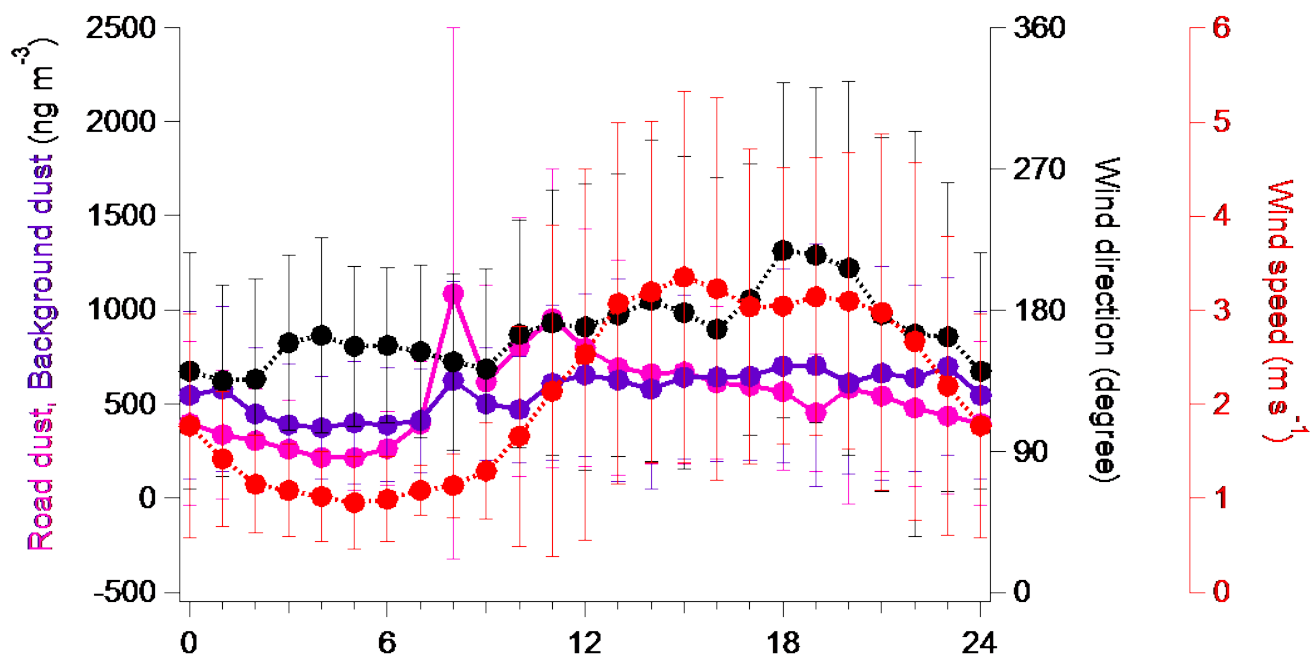

Figure S14: Mean daily patterns of the two dust factors (left-y axis) along with wind speed and wind direction (right y-axis) with error bars (one standard deviation).

\section{References}

5 Crippa, M., Canonaco, F., Lanz, V. A., Äijälä, M., Allan, J. D., Carbone, S., Capes, G., Ceburnis, D., Dall’Osto, M., Day, D. A., DeCarlo, P. F., Ehn, M., Eriksson, A., Freney, E., Hildebrandt Ruiz, L., Hillamo, R., Jimenez, J. L., Junninen, H., Kiendler-Scharr, A., Kortelainen, A.-M., Kulmala, M., Laaksonen, A., Mensah, A. A., Mohr, C., Nemitz, E., O’Dowd, C., Ovadnevaite, J., Pandis, S. N., Petäjä, T., Poulain, L., Saarikoski, S., Sellegri, K., Swietlicki, E., Tiitta, P., Worsnop, D. R., Baltensperger, U., and Prévôt, A. S. H.: Organic aerosol components derived from 25 AMS data sets across Europe using a 10 consistent ME-2 based source apportionment approach, Atmos. Chem. Phys., 14, 6159-6176, https://doi.org/10.5194/acp14-6159-2014, 2014. 